\title{
Why do patients with cancer visit the emergency department near the end of life?
}

\author{
Lisa Barbera MD MPA, Carole Taylor MSc, Deborah Dudgeon MD
}

Previously published at www.cmaj.ca

\section{ABSTRACT}

Background: For patients dying of cancer, a visit to the emergency department can be disruptive, distressing and exhausting. Such visits made near the end of life are considered an indicator of poor-quality cancer care. We describe the most common reasons for visits made to the emergency department during the final six months of life and the final two weeks of life by patients dying of cancer.

Methods: We performed a descriptive, retrospective cohort study using linked administrative sources of health care data.

Results: Between 2002 and 2005 in Ontario, 91561 patients died of cancer. Of these, 76759 patients made 194017 visits to the emergency department during the final six months of life. Further, 31076 patients made 36600 visits to the emergency department during the final two weeks of life. In both periods, the most common reasons were abdominal pain, lung cancer, dyspnea, pneumonia, malaise and fatigue, and pleural effusion.

Interpretation: Many visits made to the emergency department by patients with cancer near the end of life may be avoidable. An understanding of the reasons for such visits could be useful in the development of dedicated interventions for preventing or avoiding their occurrence.

$\mathrm{F}$ or people with cancer, a visit to the emergency department can be an ordeal. Waits for care can be long $^{1}$ and uncomfortable. ${ }^{2}$ In particular, for patients who are dying of cancer and their families, such visits can be disruptive, distressing and exhausting. Visits to the emergency department made near the end of life have been used as an indicator of poor-quality care for patients with cancer at the end of life. ${ }^{3,4}$ In Ontario, the proportion of patients who visit the emergency department during the final two weeks of life is about $40 \%{ }^{5}$ Such a visit often represents a transition in a patient's care. ${ }^{6}$ Even for those whose care is based on an established palliative approach, the visit may be precipitated by the distress of family members at end-of-life symptoms.?

Ideally, the symptoms of a patient near death would be adequately controlled and the patient would be cared for in the setting of his or her choice, rather than on an emergency basis. While some patients have unexpected urgent medical problems that result in an unavoidable emergency department visit, other such visits are likely avoidable. Understanding why this group of patients visits the emergency department is crucial for determining how best to attempt to minimize the number of patients who go to the emergency department. We describe the most common reasons for visits made to the emergency department during the final six months and the final two weeks of life among patients who die of cancer.

\section{Methods}

We performed a descriptive, retrospective study using administrative sources of health care data. We examined how often and why patients dying of cancer visited the emergency department near the end of life.

\section{Sources of data}

The Ontario Cancer Registry is a comprehensive, populationbased registry that captures $95 \%$ of all incident cases of cancer in the province. ${ }^{8,9}$ The National Ambulatory Care Reporting System captures all visits to the emergency department. The Registered Persons Database contains demographic information on all residents of Ontario who are eligible for the Ontario Health Insurance Plan. ${ }^{10}$

\section{Inclusion criteria}

We used the Ontario Cancer Registry to identify all patients who died of cancer between 2002 and 2005, as indicated by death certificates. If more than one record existed, we chose the cause of death as the record that matched the diagnosis of registration. We excluded patients for whom a diagnosis of cancer had not been made before death, whose deaths occurred within 30 days of a major cancer-related operative procedure, whose health insurance numbers were invalid during the final six months of life, who died outside of Ontario, or who were younger than 20 years of age. We linked cases using a common unique identifier.

From the Department of Radiation Oncology and the Department of Health Policy, Management and Evaluation (Barbera), University of Toronto; the Institute for Clinical Evaluative Sciences (Taylor), Toronto, Ont.; and the Palliative Care Program (Dudgeon), Queen's University, Kingston, Ont.

CMAJ 2010. DOI:10.1503/cmaj.091187 


\section{Patient variables}

We used data from the Registered Persons Database to calculated the age at death of each patient. Sex of patients was recorded from the Ontario Cancer Registry. For type of cancer recorded as the cause of death for each patient, we used the International Classification of Diseases (ICD) 9 codes of the Ontario Cancer Registry, which were grouped and coded as follows: head and neck 140-149, 160, 161; breast 174; lung 162; prostate 185 ; ovary 183 ; colorectal 153, 154 ; central nervous system 191; lymphoma or leukemia 200-208; other genitourinary or gynecological 179-182, 184, 186-189; melanoma or sarcoma 170-172; non-melanoma skin cancer 173; other gastrointestinal 150-152, 155-159; metastases 196-199; other 163-165, 190, 192-194.

\section{Outcome}

Visits made to the emergency department during the final two weeks and the final six months of life were identified in the National Ambulatory Care Reporting System. The two-week interval is currently used by Cancer Care Ontario for its Cancer System Quality Index indicator describing emergency department use at the end of life. ${ }^{5}$ The final six months of life is a commonly used interval in research on health services aimed at studying care in the palliative period. ${ }^{11}$ The documented reason for each visit to the emergency department (listed in the official record of each visit as the most responsible diagnosis) was extracted for this study. After reviewing the frequencies of each diagnostic code separately, we grouped together similar diagnoses.

During the study window, the coding system for diagnoses changed from ICD 9 to ICD 10. Common codes from each

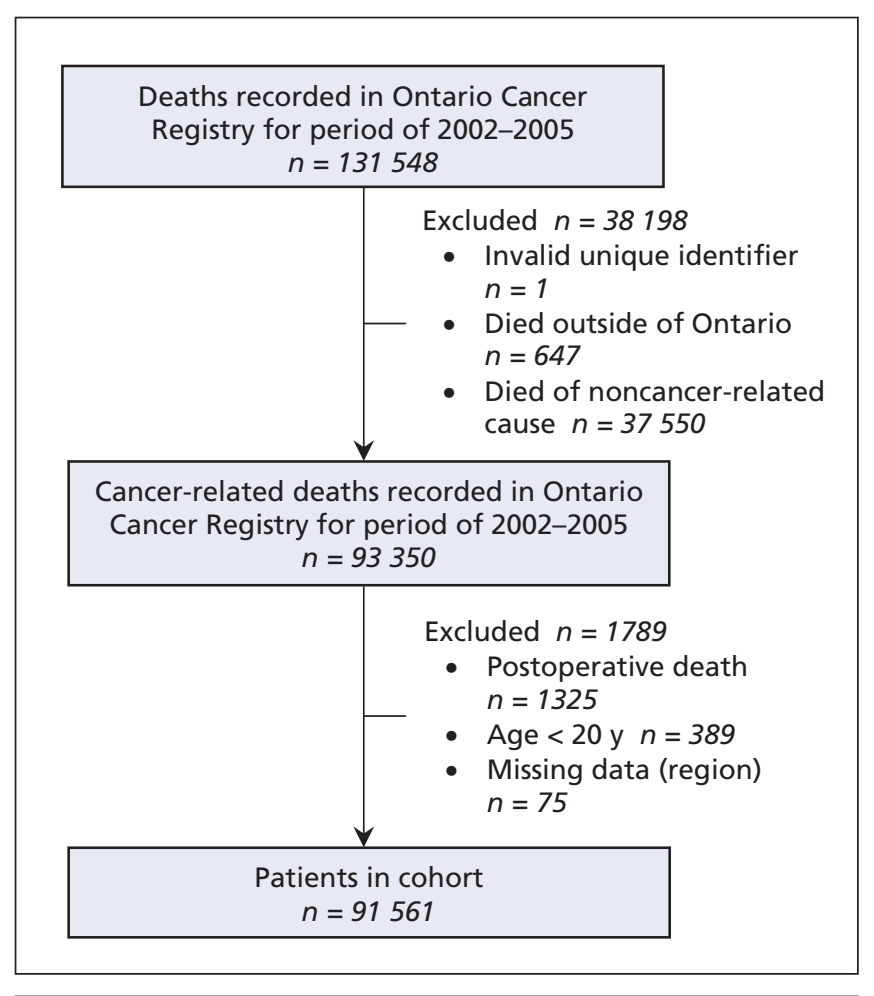

Figure 1: Flow chart showing patients included in the study. system were matched by hand by one of the authors (LB). The diagnostic labels used in our study, along with their corresponding codes, are available in Appendix 1 at www.cmaj .ca/cgi/content/full/cmaj.091187/DC1.

\section{Analysis}

We generated the frequencies of each diagnosis (i.e., reason for an emergency department visit) to create a list of the most common diagnoses. The unit of analysis was the visit (i.e., not the patient), unless otherwise specified.

\section{Results}

Between 2002 and 2005 in Ontario, 91561 patients died of cancer and were included in our cohort (Figure 1). During the final six months of life, 76759 patients made 194017 visits to the emergency department. During the final two weeks of life, 31076 patients made 36600 visits to the emergency department. Of those who visited the emergency department during the final six months of life, $36.5 \%$ made one visit, $26.8 \%$ made two, $15.9 \%$ made three, $8.9 \%$ made four, $4.9 \%$ made five, and $6.9 \%$ made six or more. Of those who visited the emergency department during the final two weeks of life, $85.3 \%$ of patients made one visit, $12.4 \%$ made two, and $2.4 \%$ made three or more.

The characteristics of all patients who died of cancer, those who visited the emergency department during the final six months or two weeks of life and those who did not visit the emergency department during the final six months of life are listed in Table 1. Patients with lung cancer were slightly overrepresented among patients who visited the emergency department, whereas patients with breast and colorectal cancer were slightly under-represented in this group.

The 30 most common reasons for visits to the emergency department made during the final six months of life are listed in Table 2; those for visits made during the final two weeks of life are listed in Table 3. These diagnoses account for about $50 \%$ or more of all visits in each period. The remaining diagnoses, which number in the hundreds, account for a fraction of a per cent each.

Lung cancer ranked second among reasons for visits made during the final six months of life and first among those for visits made during the final two weeks. The primary cancer diagnosis (i.e., for all sites counted together) was the main diagnosis recorded for $18.2 \%$ of visits made during the final two weeks of life, and for $10.9 \%$ of those made during the final six months.

The other highly ranked diagnoses that were common to both periods were abdominal pain, dyspnea, pneumonia, malaise and fatigue, and pleural effusion. A notable difference between the two time periods was the rank of cardiac arrest, which ranked 16th among diagnoses made for visits during the final two weeks but 61st among those made for visits during the final six months. Palliative care, dehydration and altered level of consciousness ranked much higher for the final two-week period than for the six-month period.

No specific code exists for pain-related crisis. We combined the diagnoses involving pain in various body sites (i.e., abdomen, chest, back or limb) and found that they accounted 
for $9.4 \%$ of visits $(n=18267)$ made during the final six months and $5.1 \%$ of visits $(n=1857)$ made during the final two weeks of life.

Visits that were made for constipation (and hence were clearly avoidable) ranked 11th among those made during the final six months of life and 31st among those made during the final two weeks. Reasons for other avoidable visits included technical or mechanical reasons, such as follow-up, laboratory examination, attention to dressings or sutures, adjustment of a urinary catheter, and prescription refills. Together, these other avoidable visits accounted for 5442 visits (2.8\%) during the final six months of life and 441 visits $(1.2 \%)$ during the final two weeks.

Clinical descriptions of patients or families as no longer "coping" at home are common. This concept is likely captured by diagnoses pertaining to malaise and fatigue, need for palliative care, and perhaps dehydration, which together accounted in our study for $5.1 \%$ of visits $(n=9902)$ during the final six months of life and $8.4 \%(n=3070)$ during the final two weeks. When considered as a group, these reasons became very highly ranked, and surpassed the rank for pain during the final two weeks of life. ${ }^{12}$

Of the visits made during the final two weeks of life, $71.9 \%$ resulted in an admission and $20.7 \%$ resulted in discharge to the patient's place of residence. In $4.8 \%$ of the visits, the patient was pronounced dead on arrival or died in the emergency department. Of the few remaining visits, patients either were transferred to another institution or left before completing treatment. Of the 31076 patients who visited the emergency department during the final two weeks of life, $77.2 \%$ died in an acute care bed, $5.2 \%$ died in the emergency department, $8.2 \%$ died in chronic or long-term care and 3.4\% died at home (the location of death could not be identified for $6 \%$ ).

Table 1: Characteristics of patients who died of cancer in Ontario in the period 2002-2005, by visits to the emergency department near the end of life

\begin{tabular}{|c|c|c|c|c|c|c|c|c|}
\hline $\begin{array}{l}\text { Characteristic } \\
\text { No. of visits made to ED }\end{array}$ & \multicolumn{2}{|c|}{$\begin{array}{c}\text { All patients }(\%)^{*} \\
n=91561\end{array}$} & \multicolumn{2}{|c|}{$\begin{array}{l}\text { No. of patients with } \geq 1 \\
\text { visit in final } 6 \mathrm{mo}(\%)^{*} \\
\quad n=76759\end{array}$} & \multicolumn{2}{|c|}{$\begin{array}{l}\text { No. of patients with } \geq 1 \\
\text { visit in final } 2 \mathrm{wk}(\%)^{*} \\
\quad n=31076\end{array}$} & \multicolumn{2}{|c|}{$\begin{array}{l}\text { No. of patients with no } \\
\text { visits in final } 6 \mathrm{mo}(\%)^{*} \\
\qquad n=14802\end{array}$} \\
\hline Age, yr, median (range) & 73 & $(20-108)$ & 73 & 20-108) & 72 & 20-104) & 74 & $(21-104)$ \\
\hline \multicolumn{9}{|l|}{ Sex } \\
\hline \multicolumn{9}{|l|}{ Year of death } \\
\hline 2002 & 22438 & (24.5) & 18370 & (23.9) & 7549 & (24.3) & 4068 & $(27.5)$ \\
\hline 2003 & 22779 & (24.9) & 19094 & (24.9) & 7679 & $(24.7)$ & 3685 & (24.9) \\
\hline 2004 & 23091 & $(25.2)$ & 19497 & $(25.4)$ & 7876 & $(25.3)$ & 3594 & (24.3) \\
\hline \multicolumn{9}{|l|}{ Type of cancer } \\
\hline Prostate & 5206 & $(5.7)$ & 4286 & $(5.6)$ & 1640 & (5.3) & 920 & $(6.2)$ \\
\hline Colorectal & 9543 & (10.4) & 7606 & $(9.9)$ & 2793 & (9.0) & 1937 & (13.1) \\
\hline $\begin{array}{l}\text { Genitourinary or } \\
\text { gynecological }\end{array}$ & 6327 & $(6.9)$ & 5272 & (6.9) & 1838 & (5.9) & 1055 & $(7.1)$ \\
\hline Ovarian & 2434 & $(2.7)$ & 1996 & (2.6) & 698 & $(2.2)$ & 438 & $(3.0)$ \\
\hline $\begin{array}{l}\text { Lymphoma or } \\
\text { leukemia }\end{array}$ & 8814 & $(9.6)$ & 7517 & $(9.8)$ & 3245 & $(10.4)$ & 1297 & $(8.8)$ \\
\hline Melanoma or sarcoma & 1941 & (2.1) & 1582 & $(2.1)$ & 621 & $(2.0)$ & 359 & $(2.4)$ \\
\hline Head and neck & 2246 & $(2.5)$ & 1804 & (2.4) & 731 & (2.4) & 442 & $(3.0)$ \\
\hline
\end{tabular}

*Unless stated otherwise.

Note: $E D$ = emergency department. 


\section{Interpretation}

As a group, all of the primary cancer sites accounted for the largest proportion of visits. Lung cancer was the most common primary cancer diagnosis. Abdominal pain, dyspnea, pneumonia, malaise and fatigue, and pleural effusion were other highly ranked diagnoses, both for visits made during the

Table 2: Reasons for visits to the emergency department by cancer patients during the final six months of life

\begin{tabular}{|c|c|c|c|c|}
\hline Rank & Reason & $\begin{array}{c}\text { Frequency } \\
n=194017\end{array}$ & $\%$ & $95 \% \mathrm{Cl}$ \\
\hline 1 & Abdominal pain & 9224 & 4.75 & $(4.66-4.85)$ \\
\hline 2 & Lung cancer & 8741 & 4.51 & $(4.41-4.60)$ \\
\hline 3 & Pneumonia & 6924 & 3.57 & $(3.49-3.65)$ \\
\hline 4 & Dyspnea & 6171 & 3.18 & $(3.01-3.26)$ \\
\hline 5 & $\begin{array}{l}\text { Malaise and } \\
\text { fatigue }\end{array}$ & 4972 & 2.56 & $(2.49-2.63)$ \\
\hline 6 & Chest pain & 4463 & 2.30 & $(2.23-2.37)$ \\
\hline 7 & Pleural effusion & 3667 & 1.89 & $(1.83-1.95)$ \\
\hline 8 & $\begin{array}{l}\text { Nausea or } \\
\text { vomiting }\end{array}$ & 3525 & 1.82 & $(1.76-1.88)$ \\
\hline 9 & Anemia & 3513 & 1.81 & $(1.75-1.87)$ \\
\hline 10 & Back pain & 3460 & 1.78 & $(1.72-1.84)$ \\
\hline 11 & Constipation & 3392 & 1.75 & $(1.69-1.81)$ \\
\hline 12 & Fever & 3174 & 1.64 & $(1.58-1.69)$ \\
\hline 13 & Dehydration & 3146 & 1.62 & $(1.57-1.68)$ \\
\hline 14 & COPD & 3074 & 1.58 & $(1.53-1.64)$ \\
\hline 15 & $\begin{array}{l}\text { Urinary tract } \\
\text { infection }\end{array}$ & 3012 & 1.55 & $(1.50-1.61)$ \\
\hline 16 & $\begin{array}{l}\text { Intestinal } \\
\text { obstruction }\end{array}$ & 2879 & 1.48 & $(1.43-1.54)$ \\
\hline 17 & $\begin{array}{l}\text { Altered } \\
\text { consciousness }\end{array}$ & 2866 & 1.48 & $(1.42-1.53)$ \\
\hline 18 & $\begin{array}{l}\text { Congestive heart } \\
\text { failure }\end{array}$ & 2396 & 1.23 & $(1.19-1.28)$ \\
\hline 19 & $\begin{array}{l}\text { Gastrointestinal } \\
\text { hemorrhage }\end{array}$ & 2055 & 1.06 & $(1.01-1.10)$ \\
\hline 20 & Palliative care & 1784 & 0.92 & $(0.88-0.96)$ \\
\hline 21 & Chemotherapy & 1775 & 0.91 & $(0.87-0.96)$ \\
\hline 22 & Pancreatic cancer & 1721 & 0.89 & $(0.85-0.93)$ \\
\hline 23 & Neutropenia & 1716 & 0.88 & $(0.84-0.93)$ \\
\hline 24 & Colon cancer & 1714 & 0.88 & $(0.84-0.93)$ \\
\hline 25 & Ascites & 1699 & 0.88 & $(0.83-0.92)$ \\
\hline 26 & $\begin{array}{l}\text { Retention of } \\
\text { urine }\end{array}$ & 1617 & 0.83 & $(0.79-0.87)$ \\
\hline 27 & $\begin{array}{l}\text { Phlebitis or } \\
\text { thrombophlebitis }\end{array}$ & 1616 & 0.83 & $(0.79-0.87)$ \\
\hline 28 & Hematuria & 1527 & 0.79 & $(0.75-0.83)$ \\
\hline 29 & Breast cancer & 1423 & 0.73 & $(0.70-0.77)$ \\
\hline \multirow[t]{2}{*}{30} & Convulsions & 1355 & 0.70 & $(0.66-0.74)$ \\
\hline & Other & 95416 & 49.18 & (48.96-49.40) \\
\hline
\end{tabular}

Note: COPD = Chronic obstructive pulmonary disease. final six months and those made during the final two weeks of life. When we further collapsed the diagnoses, we observed that pain and failure to cope were very common. Numerous visits to the emergency department may be avoidable.

Our study provides an overview of why patients with cancer use the emergency department near the end of life. It includes all cancer diagnoses and is population-based. It adds substantially to the sparse data available about both palliative patients with cancer and the emergency department.

Our findings are similar to those of another Ontario study in which Barbera and colleagues ${ }^{13}$ described the presenting chief complaints and admitting diagnoses among a sample cohort of deceased patients with lung cancer. Our current study is more comprehensive and involves a more recent period. A study from Nova Scotia involving patients enrolled in a palliative care program reported similar reasons for visits to the emergency department. ${ }^{14}$ Single-institution reviews involving patients with cancer who visited the emergency department show that progressive malignancy and dyspnea are common symptoms at the end of life and are associated with a poor prognosis. ${ }^{15,16}$

We draw several inferences from this study. Ideally, people who are dying of cancer would be able to avoid emergency department visits near the end of life. Although the majority of the visits made during the final two-week interval led to admission, this result does not mean that the patients involved could be managed only in an acute care facility. Rather, it suggests that the quantity and quality of their care was not sufficient to address their needs or the needs of their caregivers. Patients who are failing at home are unlikely to need to visit the emergency department. Instead, these patients require either additional support to remain at home or direct transfer to a palliative care unit or residential hospice.

With comprehensive and coordinated palliative care, individual patients could be managed in clinics, at home and in palliative care units or residential hospices without the need for a visit to the emergency department. The majority of the reasons for visits are within the scope of palliative care expertise. A high-quality palliative care team would reasonably be expected to be able to address symptoms such as pain, dyspnea, nausea and vomiting, constipation, malaise and fatigue.

With an understanding of why patients visit the emergency department, dedicated interventions to prevent or avoid such visits become more tangible. First, impeccable control of symptoms, especially dyspnea, pain and constipation, is critical. Standardized assessments and practice guidelines shared among all providers could be a useful intervention. Continuity of provider ${ }^{17}$ and information are likely also important. Other interventions could be considered as well to reduce visits to the emergency department. For example, caregiver education could play a role. Structured psycho-educational interventions $^{18,19}$ could help family members and caregivers to anticipate, identify and cope with a situation as an expected crisis, rather than an emergency, ${ }^{20}$ and perhaps influence decisions to go to the emergency department. Directives issued in advance might influence the decision to go to the emergency depart- 
ment or facilitate decision-making for and management of common problems such as pneumonia. However, a minority of patients with cancer complete advanced directives. ${ }^{21,22}$ Finally, increasing the capacity or expertise for patient care in the home might address technical or mechanical problems, such as attention to dressings, sutures, and catheters as well as the need for follow-up visits, repeat prescriptions and laboratory examinations.

Table 3: Reasons for visits to the emergency department by cancer patients during the final two weeks of life

\begin{tabular}{|c|c|c|c|c|}
\hline Rank & Reason & $\begin{array}{l}\text { Frequency } \\
n=36600\end{array}$ & $\%$ & $(95 \% \mathrm{Cl})$ \\
\hline 1 & Lung cancer & 3242 & 8.86 & (8.57-9.15) \\
\hline 2 & Dyspnea & 1844 & 5.04 & $(4.81-5.26)$ \\
\hline 3 & Pneumonia & 1832 & 5.01 & $(4.78-5.23)$ \\
\hline 4 & Abdominal pain & 1126 & 3.08 & $(2.90-3.25)$ \\
\hline 5 & Malaise and fatigue & 1084 & 2.96 & $(2.79-3.14)$ \\
\hline 6 & Palliative care & 1042 & 2.85 & $(2.68-3.02)$ \\
\hline 7 & Dehydration & 944 & 2.58 & $(2.42-2.74)$ \\
\hline 8 & Pleural effusion & 717 & 1.96 & $(1.82-2.10)$ \\
\hline 9 & $\begin{array}{l}\text { Altered } \\
\text { consciousness }\end{array}$ & 689 & 1.88 & $(1.74-2.02)$ \\
\hline 10 & Pancreatic cancer & 585 & 1.60 & $(1.47-1.73)$ \\
\hline 11 & Colon cancer & 580 & 1.58 & $(1.46-1.73)$ \\
\hline 12 & $\begin{array}{l}\text { Congestive heart } \\
\text { failure }\end{array}$ & 521 & 1.42 & $(1.30-1.54)$ \\
\hline 13 & $\begin{array}{l}\text { Intestinal } \\
\text { obstruction }\end{array}$ & 484 & 1.32 & $(1.21-1.44)$ \\
\hline 14 & Breast cancer & 475 & 1.30 & $(1.18-1.41)$ \\
\hline 15 & $\begin{array}{l}\text { Gastrointestinal } \\
\text { hemorrhage }\end{array}$ & 468 & 1.28 & $(1.16-1.39)$ \\
\hline 16 & Cardiac arrest & 466 & 1.27 & $(1.16-1.39)$ \\
\hline 17 & Nausea or vomiting & 460 & 1.26 & (1.14-.37) \\
\hline 18 & COPD & 448 & 1.22 & $(1.11-1.34)$ \\
\hline 19 & Anemia & 446 & 1.22 & $(1.11-1.33)$ \\
\hline 20 & $\begin{array}{l}\text { Malignant } \\
\text { neoplasm* }\end{array}$ & 434 & 1.19 & $(1.07-1.30)$ \\
\hline 21 & Lung metastasis & 403 & 1.10 & $(0.99-1.21)$ \\
\hline 22 & $\begin{array}{l}\text { Non-Hodgkins } \\
\text { lymphoma* }\end{array}$ & 381 & 1.04 & $(0.94-1.14)$ \\
\hline 23 & Renal failure & 379 & 1.04 & $(0.93-1.14)$ \\
\hline 24 & Chest pain & 376 & 1.03 & $(0.92-1.13)$ \\
\hline 25 & Septicemia & 368 & 1.01 & $(0.90-1.11)$ \\
\hline 26 & Prostate cancer & 358 & 0.98 & $(0.88-1.08)$ \\
\hline 27 & $\begin{array}{l}\text { Urinary tract } \\
\text { infection }\end{array}$ & 328 & 0.90 & $(0.80-0.99)$ \\
\hline 28 & Ascites & 305 & 0.83 & $(0.74-0.93)$ \\
\hline 29 & Fever & 292 & 0.80 & $(0.71-0.89)$ \\
\hline \multirow[t]{2}{*}{30} & Neutropenia & 281 & 0.77 & $(0.68-0.86)$ \\
\hline & Other & 15242 & 41.64 & (41.14-42.15) \\
\hline
\end{tabular}

Note: COPD = Chronic obstructive pulmonary disease.

*Type unspecified.

\section{Limitations}

The limitations of this study include those typical of studies relying on administrative data. The quality of the main diagnosis variable in the National Ambulatory Care Reporting System is of specific interest for our results. Re-abstraction studies of the main diagnosis variable show $69 \%$ perfect agreement with an additional $9 \%$ category agreement. ${ }^{23}$ Given that we created larger diagnostic groups of similar diagnoses for our study, the impact of this error is diminished. Use of cause-of-death data obtained from death certificates can be problematic ${ }^{24}$ but is a commonly used method to identify patients who died of cancer. ${ }^{11,25,26}$

A larger problem with the ICD system, which was designed for general purposes, is that it is not well suited for describing problems in a population of dying patients with cancer ${ }^{23}$ For example, listing the cancer diagnosis as the reason for a visit does not provide information about the precipitating event that led to visiting the emergency department, and hence limits interpretation. Pain is likely under-represented with our methods as well. Some diagnoses are associated with pain, but are not specifically coded as such (e.g., bone metastases). Also, our methods allow for one diagnosis per visit. This patient population has complex symptom issues involving multiple problems.

\section{Conclusion}

Understanding why patients visit the emergency department near the end of life provides insight into the nature of the problems they experience and provides direction for possible interventions. In 2006, Ontario started a program of systematic assessment of symptom severity and performance status with standardized tools. The goal was to improve symptom assessment and control. Pilot data from this project suggest that visits to the emergency department decreased. ${ }^{27}$ Further assessment will be required to determine the impact of this project at a provincial level.

This article has been peer reviewed.

Competing interests: Deborah Dudgeon is Clinical Lead for the Palliative Care Committee at Cancer Care Ontario.

Contributors: All of the authors were involved in the conceptual design of the study. Lisa Barbera and Carole Taylor were involved in the analysis of the data. Lisa Barbera and Deborah Dudgeon were involved in the interpretation of the data. Lisa Barbera and Deborah Dudgeon drafted the manuscript and Lisa Barbera wrote the final version. All authors critically reviewed the manuscript for important intellectual content and approved the final version submitted for publication.

Acknowledgement: The authors thank Dr. Gillian Thomas for her helpful comments on the manuscript.

Funding: Dr. Barbera is a career scientist with the Ontario Ministry of Health and Long-Term Care. Portions of this work were originally prepared for the Ontario Cancer System Quality Index. Cancer Care Ontario was not involved in the design of the study, analysis, interpretation of the data, drafting of the manuscript or decision to submit for publication. The views expressed in this paper do not necessarily reflect those of Cancer Care Ontario.

This study was supported by the Institute for Clinical Evaluative Sciences (ICES), which is funded by an annual grant from the Ontario Ministry of Health and Long-Term Care (MOHLTC). The opinions, results and conclusions reported in this paper are those of the authors and are independent from the funding sources. No endorsement by ICES or the Ontario MOHLTC is intended or should be inferred. 


\section{REFERENCES}

1. Rowe B, Bond K, Ospina M, et al. Frequency, determinants, and impact of over crowding in emergency departments in Canada: a national survey of emergency department directors. Ottawa (ON): Canadian Agency for Drugs and Technologies in Health; 2006. Available: www.cadth.ca/media/pdf/320c_Overcrowding_tr_e _no-appendices.pdf (accessed 2010 Jan. 4).

2. Hwang U, Richardson L, Livote E, et al. Emergency department crowding and decreased quality of pain care. Acad Emerg Med 2008

3. Barbera L, Paszat L, Chartier C. Indicators of poor quality care in end of life cancer care in Ontario. J Palliat Care 2006;22:12-7.

4. Earle CC, Park ER, Lai B, et al. Identifying potential indicators of the quality of end-of-life cancer care from administrative data. J Clin Oncol 2003;21:1133-8.

5. Cancer System Quality Index. Toronto $(\mathrm{ON})$ : Cancer Care Ontario; 2009. Available: http://csqi.cancercare.on.ca (accessed 2010 Jan. 4).

6. Chan GK. End-of-life models and emergency department care. Acad Emerg Med 2004;11:79-86.

7. Smith AK, Fisher J, Schonberg MA, et al. Am I doing the right thing? Provider perspectives on improving palliative care in the emergency department. Ann Emerg Med 2008

8. Clarke EA, Marrett LD, Kreiger N. Cancer registration in Ontario: a computer approach. In: Jenson OM, Parkin DM, MacLennan R, editors. Cancer registration principles and methods. Lyon (France): IARC Pub; 1991. p. 246-57.

9. Robles SC, Marrett LD, Clarke EA, et al. An application of capture-recapture methods to the estimation of completeness of cancer registration. J Clin Epidemiol 1988;41:495-501.

10. Iron K, Zagorski BM, Sykora K, et al. Living and dying in Ontario: an opportunity for improved health information. ICES investigative report. Toronto $(\mathrm{ON})$ : Institute for Clinical Evaluative Sciences; 2008. Available: www.ices.on.ca/file/Living _and_dying_in_Ontario_March19-08.pdf (accessed 2010 Jan. 4).

11. Huang J, Boyd C, Tyldesley S, et al. Time spent in hospital in the last six month of life in patients who died of cancer in Ontario. J Clin Oncol 2002;20:1584-92.

12. Canadian triage and acuity scale. Ottawa (ON): Canadian Association of Emergency Physicians; 2010. Available: www.caep.ca/template.asp?id =B795164082374289BBD9C1C2BF4B8D32 (accessed 2010 Jan. 4).

13. Barbera L, Paszat L, Qiu F. End-of-life care in lung cancer patients in Ontario: aggressiveness of care in the population and a description of hospital admissions. J Pain Symptom Manage 2008;35:267-74.

14. Lawson BJ, Burge FI, McIntyre P, et al. Palliative care patients in the emergency department. J Palliat Care 2008;24:247-55.
15. Geraci JM, Tsang W, Valdres RV, et al. Progressive disease in patients with cancer presenting to an emergency room with acute symptoms predicts short-term mortality. Support Care Cancer 2006;14:1038-45.

16. Escalante CP, Martin CG, Elting LS, et al. Dyspnea in cancer patients. Etiology, resource utilization, and survival-implications in a managed care world. Cancer 1996;78:1314-9.

17. Burge F, Lawson B, Johnston G. Family physician continuity of care and emergency department use in end-of-life cancer care. Med Care 2003;41:992-1001.

18. Hudson P, Thomas T, Quinn K, et al. Teaching family carers about home-based palliative care: final results from a group education program. J Pain Symptom Manage 2009;38:299-308.

19. McMillan SC, Small BJ, Weitzner M, et al. Impact of coping skills intervention with family caregivers of hospice patients with cancer: a randomized clinical trial. Cancer 2006;106:214-22.

20. Nauck F, Alt-Epping B. Crises in palliative care - a comprehensive approach. Lancet Oncol 2008;9:1086-91.

21. Levin TT, Li Y, Weiner JS, et al. How do-not-resuscitate orders are utilized in cancer patients: timing relative to death and communication-training implications. Palliat Support Care 2008;6:341-8.

22. Bradley NM, Sinclair E, Danjoux C, et al. The do-not-resuscitate order: incidence of documentation in the medical records of cancer patients referred for palliative radiotherapy. Curr Oncol 2006;13:47-54.

23. Canadian Institute for Health Information. CIHI data quality study of Ontario emergency department visits for fiscal year 2004-2005. Ottawa (ON): 2007. Available: http://secure.cihi.ca/cihiweb/products/vol1_nacrs_executive_summary_nov2 2007.pdf (accessed 2010 Jan. 4).

24. Hall S, Schulze K, Groome P, et al. Using cancer registry data for survival studies: the example of the Ontario Cancer Registry. J Clin Epidemiol 2006;59:67-76.

25. Gagnon B, Mayo NE, Laurin C, et al. Identification in administrative databases of women dying of breast cancer. J Clin Oncol 2006;24:856-62

26. Neutel CI, Bishop ML, Harper SD, et al. Proportion of cancer deaths occurring in hospital, Canada, 1994-2000. Can J Public Health 2005;96:264-8.

27. Dudgeon DJ, Knott C, Eichholz M, et al. Palliative Care Integration Project (PCIP) quality improvement strategy evaluation. J Pain Symptom Manage 2008;35:573-82.

\section{Correspondence to: Dr. Lisa Barbera, Department of Radiation}

Oncology, Odette Cancer Centre, 2075 Bayview Ave., Toronto ON M4N3M5; lisa.barbera@sunnybrook.ca
TALK TO YOUR PATIENTS ABOUT NON-SURREICALL

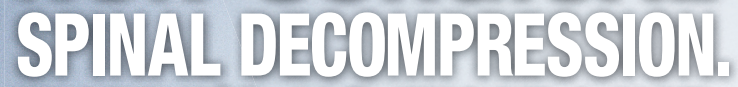
WHERES NO TIMTE LIKE

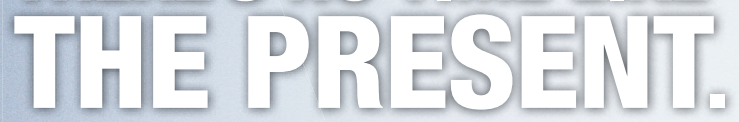

When a suitable candidate presents with a case of treatable neck or lower back pain, true non-surgical spinal decompression therapy can quite often be the best recommendation. This non-invasive approach to treating chronic neck or lower back conditions offers one more option to patients looking for a way to end the pain.

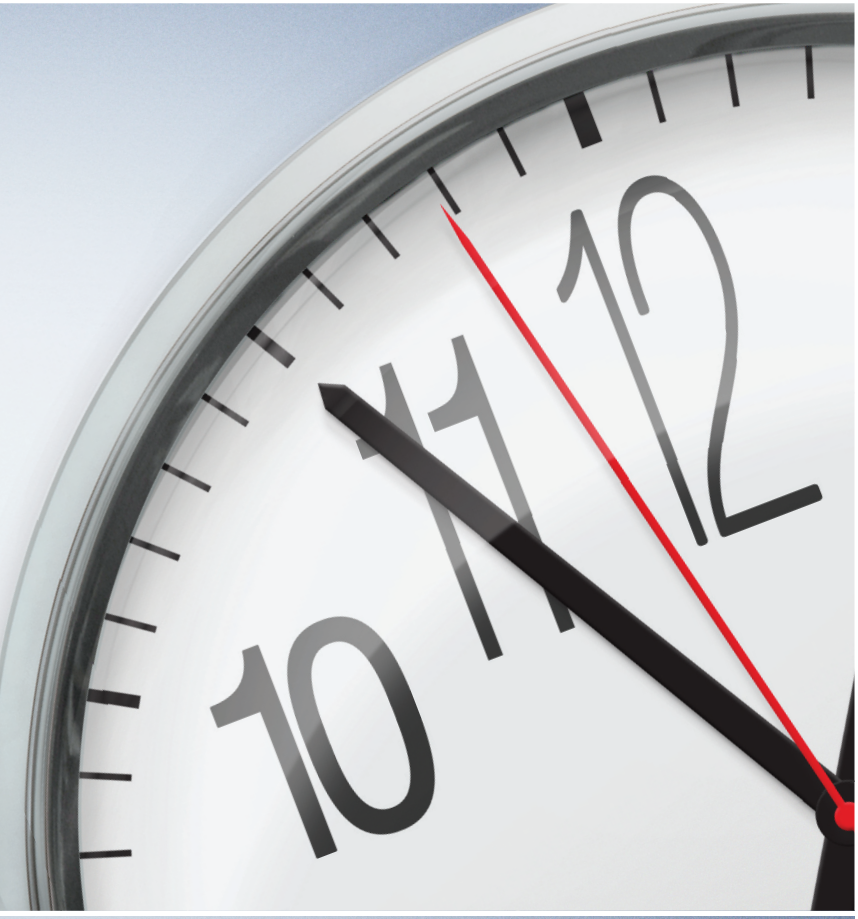

GET YOUR FREE DOGTOR KIT TODAY AT www.spinal decompression kit.com Our free Information Kit will help you better determine which patients are good candidates for true non-surgical spinal decompression.

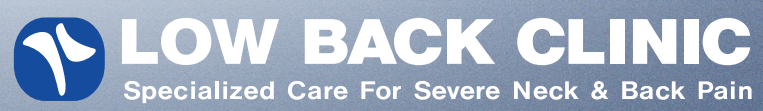

